\title{
Examination of the Protection Offered by Current Accessibility Acts and Guidelines to People with Disabilities in Using Information Technology Devices
}

\author{
Hyun K. Kim ${ }^{1}$ and Jaehyun Park ${ }^{2, *(1)}$ \\ 1 School of Information Convergence, Kwangwoon University, Seoul 01897, Korea; hyunkkim@kw.ac.kr \\ 2 Department of Industrial and Management Engineering, Incheon National University (INU), \\ Incheon 22012, Korea \\ * Correspondence: jaehpark@inu.ac.kr
}

Received: 8 April 2020; Accepted: 29 April 2020; Published: 30 April 2020

check for updates

\begin{abstract}
Today, information technology (IT) products are extensively used in everyday life; however, disabled people still experience difficulties in using them. To ensure the equal use of IT products by people with disabilities, various laws/guidelines/standards have been established. In particular, Section 508 of the Rehabilitation Act, 21st-Century Communications and Video Accessibility Act, the European Accessibility Act, and the Web Content Accessibility Guidelines strongly influence IT product sales and, hence, have been included in the scope of this research. This study analyzed the main accessibility provisions/guidelines from the user experience (UX) perspective and the IT device difficulties that are addressed by the provisions/guidelines. Accordingly, the study used the IT interaction disability concept, which analyzes the comprehensive difficulties associated with the use of an IT device from the perspective of interaction, to map each task-user interface-context factor. Finally, this study suggests the aspects to be considered while establishing accessibility provisions/guidelines. Moreover, it clarifies the provisions and guidelines for IT product designers and developers by analyzing them from the UX perspective.
\end{abstract}

Keywords: disability; accessibility; accessibility acts; accessibility guidelines; accessibility standards

\section{Introduction}

Today, information technology (IT) products are indispensable in everyday life. People extensively use smartphones, connected televisions, personal computers, and tablets nowadays and are expected to use even more IT devices in the future because of the widespread popularity of the Internet of Things [1-3]. However, despite the rapid growth in the use and number of IT devices, some people experience difficulties while using such devices.

Digital literacy is an important requirement for people to efficiently use IT devices; also it refers to the ability to understand the content of information received through IT devices and transform this information to different formats for specific purposes [4,5]. The unequal distribution of digital literacy causes the digital divide, resulting in the alienation of some people from IT devices. The digital divide refers to the economic and social imbalances between those who have access to IT and those who do not $[6,7]$. In general, the economic and social inequalities resulting from the digital divide severely affect the life of people with physical or mental disabilities [8]. Particularly for users with physical and mental disabilities, digital literacy is directly associated with the individuals' user experience (UX) accessibility. In this case, accessibility refers to the characteristic of a product or system that enables its use by people with disabilities [9-12]. When the product's accessibility level is low, people with disabilities find it difficult to use the product. Further, people with disabilities lack digital literacy 
and eventually experience the inequality caused by the digital divide. Therefore, to bridge the digital divide experienced by people with disabilities, it is necessary to increase IT devices' accessibility and, thereby, improve the people's ability to use IT devices.

Worldwide, many acts, guidelines, and standards pertaining to accessibility have been suggested to compensate the digital divide experienced by people with disabilities [13]. In the United States, which is one of the world leaders in the enactment of accessibility laws, the Americans with Disability Act [14] and Section 508 of the Rehabilitation Act of 1973 (hereafter, Section 508) [15] are particularly important. Subsequently, the 21st-Century Communications and Video Accessibility Act (CVAA), which was established in the era of President Obama, was first enacted in 2010 [16]. Subsequently, the European Accessibility Act (EAA) of 2019 was established [17]. Further, the Web Content Accessibility Guidelines (WCAGs) established in 1999 were updated to version 2.1 in May 2018 through continuous revision [18]. Currently, efforts are underway to establish/revise accessibility standards. Starting with the "Guidelines for standards developers to address the needs of older persons and persons with disabilities" developed in 2001 [19], such efforts have been progressing with particular focus on new products/services.

The purpose of this study is to analyze the major legal provisions and guidelines related to accessibility from the UX perspective. Accordingly, the study analyzes the primary accessibility provisions/guidelines related to IT devices and services using the concept of IT interaction disability (ITID) to determine the difficulties addressed by these provisions/guidelines. Section 2 introduces the ITID concept and task-interface-context (TIC) framework, which depicts the difficulties faced by people when using IT devices. From the UX perspective, ITID is a suitable concept for accessibility analysis because it recognizes the difficulty of using IT devices in terms of interaction. Section 3 reviews several important accessibility provisions, guidelines, and standards, and Section 4 introduces the process of ITID classification by analyzing detailed provisions and guidelines. Further, Section 5 presents the results of the ITID derived from Section 4 analyzed using task, user interface, and context. Finally, Section 6 discusses the research results and Section 7 presents the study's conclusions.

\section{IT Interaction Disability and Framework}

\subsection{Introduction to ITID}

ITID refers to the comprehensive difficulty experienced by people while using an IT device, and this difficulty encompasses not only the situation of using media content but also the difficulties that arise when using the IT device's hardware and software, as shown in Figure 1 [3]. This suggests a new perspective for accessibility, in terms of interaction using products, rather than individuals' physical or mental disabilities.

\section{The scope of ITID}

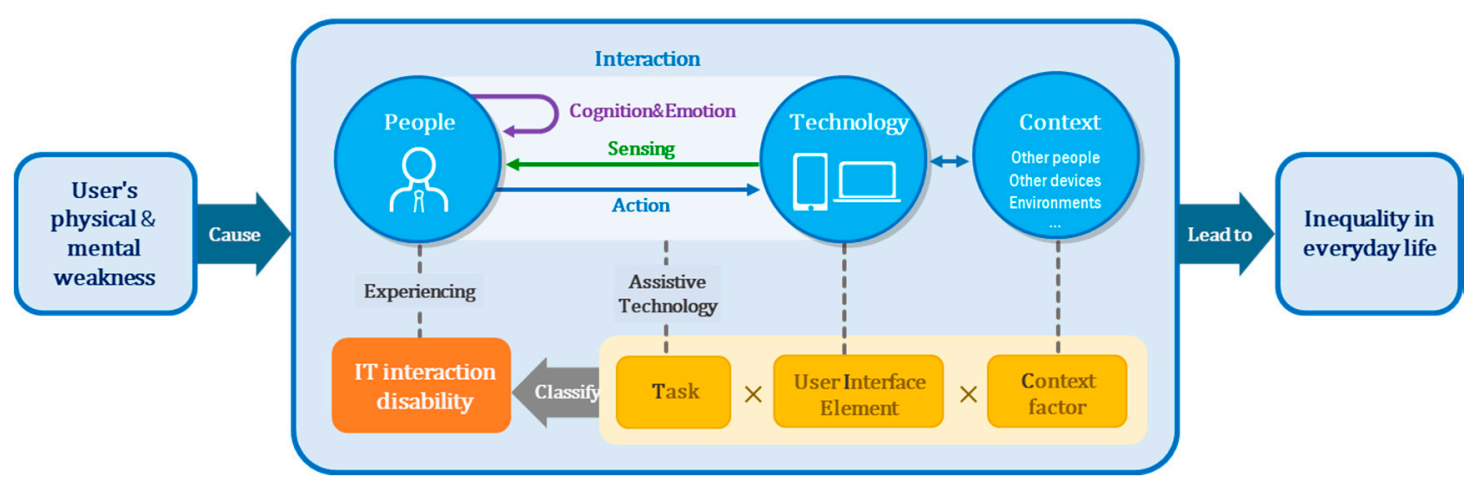

Figure 1. Depiction of the information technology interaction disability and task-interface-context framework. 
Digital literacy is a concept similar to ITID that indicates whether a user can communicate by recognizing information from a digital platform. It mainly focuses on the lack of reading skills of visual details, navigation skills, and search skills, which are cognitive skills that require the use of digital information [4]. Some similar concepts include computer literacy [20], media literacy [21], and Internet literacy [22]. ITID considers the cognitive aspects of digital literacy, as well as individuals' sensing difficulties and actionability in using digital products. In other words, ITID reflects not only cognition-related disorders but also challenges experienced by users with sensing or action-related disorders.

Table 1 depicts the five attributes of ITID [3]. They are about which difficulties that arise when using IT devices are included in ITID. For example, a user has difficulties when using a smartphone, but if he/she can use it quite well through the text to speech function, it is not included in the ITID category due to the attribute number B (Table 1). The five difficulties in Table 1 can create a digital divide by impeding people with disabilities' use of IT devices and, ultimately, depriving these people of the economic and social benefits of using such devices. Therefore, the ITID attributes can create inequities in the use of IT devices by people with disabilities.

Table 1. Five attributes of the ITID concept [3].

\begin{tabular}{ll}
\hline A. Significant difficulties that make the use of an IT device impossible, although people try \\
their best and spend a long time trying to use it \\
Significant difficulties that make interactions with an IT device impossible, although people \\
use a specific type of assistive technology to improve the accessibility of an IT device \\
Significant difficulties that cannot be overcome by people without other people's assistance \\
while using IT devices \\
D. Significant difficulties that cause people to stop trying to learn how to use IT devices \\
E. Signite receiving help or instruction from other users
\end{tabular}

ITID, information technology interaction disability.

ITID is divided into four types, of which classify the characteristics of the ITID. ITID on sensing refers to difficulties experienced in obtaining information from sensory periods, such as sight, sound, and touch. Further, ITID on cognition implies a difficulty in analyzing the information obtained from sensory organizations, such as understanding and interpretation, through an information-processing process. Finally, ITID on emotion is a difficulty in recognizing and interpreting emotions, and ITID on action is the difficulty in performing the IT device's functions and is related to the user's ability to operate the equipment. Four types of ITID are highly linked with conventional disability types. Table 2 shows the relationship between four types of ITID and disability types.

Table 2. ITID and disability types.

\begin{tabular}{cc}
\hline ITID Types & Relevant Disability Types \\
\hline ITID on sensing & sensory disability \\
ITID on cognition & specific learning disability, digital illiteracy, intellectual disability \\
ITID on emotion & emotional disability \\
ITID on action & physical disability, speech disorder, language disorder \\
\hline
\end{tabular}

ITID, information technology interaction disability.

\subsection{Task-Interface-Context Framework}

The TIC framework involves three components: tasks, user interface elements (UIEs), and context factors (Figure 1). The main characteristic of ITID is that users can experience it when they perform "tasks" while interacting with the UIEs of IT devices in a certain context. By combining these three components, the types of ITID can be classified systematically. For example, "Significant difficulty in seeing visual information on the screen outside in bright sunlight" can be classified into "Receive" 
$\times$ "Visual information" $\times$ "Outside and light levels" using the TIC framework. The International Classification of Functioning, Disability and Health (ICF) is the World Health Organization's framework for understanding functioning, disability, health-related states, outcomes, and determinants [23]. Relevant ICF codes were added in Tables 3-5.

Table 3. An IT device task taxonomy.

\begin{tabular}{|c|c|c|}
\hline Category & Task & ICF Code \\
\hline sensing & notice, search, receive & d110 d129, \\
\hline cognition & $\begin{array}{c}\text { recognize, understand, manage, learn, decide, } \\
\text { remember, engage }\end{array}$ & d130-d159, d160-d179 d310-d329 \\
\hline emotion & enjoy, challenge, like, approve & - \\
\hline $\begin{array}{l}\text { action for information } \\
\text { interaction }\end{array}$ & $\begin{array}{l}\text { activate, edit, choose, input data, create, } \\
\text { eliminate, control, manipulate, exchange }\end{array}$ & d330-d349, d350-d369 \\
\hline $\begin{array}{l}\text { action for physical } \\
\text { device setting }\end{array}$ & position, connect, grasp & $\mathrm{d} 430, \mathrm{~d} 440$ \\
\hline
\end{tabular}

IT, information technology.

Table 4. UIEs of IT devices.

\begin{tabular}{ccc}
\hline Group & UIEs & ICF Code \\
\hline hardware & user input, main body, system output & - \\
\cline { 1 - 2 } software & visual information & - \\
& information item $\quad \begin{array}{c}\text { auditory information } \\
\text { tactile information }\end{array}$ & - \\
\cline { 2 - 3 } & functional item & - \\
& structural item & - \\
\hline
\end{tabular}

IT, information technology; UIE, user interface element.

Table 5. Contextual taxonomies of IT devices.

\begin{tabular}{ccc}
\hline Category & Context Factors & ICF Code \\
\hline user & profile, preference, previous experience, status, activity, location & - \\
other people & communication media, relationship, device, context & eE310 e360 \\
environment & physical surroundings, technical surroundings, time & e125 \\
device & distance, status, charge, brand, function & - \\
\hline
\end{tabular}

IT, information technology.

Tasks can be defined as the observable units of activities that are performed to achieve a goal [24,25]. The task taxonomy was analyzed using the following procedures: (1) Collecting tasks by conducting literature reviews from human computer interaction, literacy, activities of people with disabilities, and hedonic experience; (2) selecting important tasks by conducting an expert survey with the help of five hands-on UX experts in a Korean IT company; (3) verifying an IT device task taxonomy using IT device user guides; and (4) analyzing an IT device task taxonomy. Table 3 depicts an IT device task taxonomy.

UIEs are the components of IT devices in which interactions occur while users perform tasks using the devices [26]. They hierarchically comprise hardware (the physical part) and software (the logical part) (Table 4). The hardware of UIEs of IT devices is further classified into user input components, system output components, and the main body of the device $[27,28]$, whereas the software of UIEs comprises the programmed elements that appear on a display panel [26]. The software of UIEs is composed of three parts: informational, functional, and structural items.

Further, context is defined as a set of conditions that influences users' interaction with a device [29]. Contextual taxonomies were developed by surveying the context factors that influence the UX of 
IT devices [30,31] and situationally-induced impairments [32,33]. Table 5 presents the contextual taxonomies of IT devices.

\section{Literature Review on Accessibility Acts/Guidelines/Standards}

To date, various accessibility provisions, guidelines, and standards have been enacted or revised worldwide, and specific guidelines are used for specific purposes (Table 6).

Table 6. Major accessibility acts/guidelines/standards.

\begin{tabular}{|c|c|c|c|}
\hline Category & Title of Standard & Published & Contents \\
\hline \multirow{2}{*}{ Act } & $\begin{array}{l}\text { 21st CVAA (21st Communications and Video } \\
\text { Accessibility Act) [16] }\end{array}$ & $\begin{array}{l}\text { 2010, } \\
\text { the United States }\end{array}$ & $\begin{array}{l}\text { Accessibility rights pertaining to modern IT devices, } \\
\text { which include advanced communications services } \\
\text { (e.g., text messaging, e-mailing, and videos) }\end{array}$ \\
\hline & European Accessibility Act [17] & 2015, Europe & $\begin{array}{c}\text { Accessibility rights pertaining to IT devices products, } \\
\text { services, and infrastructures in Europe }\end{array}$ \\
\hline \multirow{3}{*}{ Guideline } & Web Content Accessibility Guidelines 2.1 [18] & 2018 & $\begin{array}{l}\text { Guidelines that provide a single standard for web } \\
\text { content accessibility for people with disabilities }\end{array}$ \\
\hline & Samsung Accessibility UX Design Guide [13] & Samsung & $\begin{array}{c}\text { Guidelines to consider critical accessibility-related } \\
\text { issues for UX designers }\end{array}$ \\
\hline & $\begin{array}{c}\text { The BBC Standards and Guidelines for Mobile } \\
\text { Accessibility [39] }\end{array}$ & BBC & $\begin{array}{l}\text { Accessibility guidelines related to mobile web } \\
\text { content, hybrid, and native applications with } \\
\text { example codes for implementation in HTML, } \\
\text { Android, and iOS and steps for testing }\end{array}$ \\
\hline \multirow{6}{*}{ ISO Standard } & $\begin{array}{c}\text { Guidelines for standards developers to address the } \\
\text { needs of older persons and persons with } \\
\text { disabilities [19] }\end{array}$ & 2001 & $\begin{array}{l}\text { It summarizes the requirements for usability and } \\
\text { accessibility of the elderly and people with } \\
\text { disabilities and analyzes the aspects to be considered } \\
\text { when designing the actual product and service }\end{array}$ \\
\hline & $\begin{array}{l}\text { Information technology-Accessibility } \\
\text { considerations for people with disabilities-Part 2: } \\
\text { Standards inventory [41] }\end{array}$ & 2009 & $\begin{array}{l}\text { Identifies a collection of standards that satisfies the } \\
\text { needs of people with disabilities from part } 1\end{array}$ \\
\hline & $\begin{array}{l}\text { Information technology-Accessibility } \\
\text { considerations for people with disabilities-Part 3: } \\
\text { Guidance on user needs mapping [42] }\end{array}$ & 2009 & $\begin{array}{l}\text { Guidance on the mapping of a set of user needs with } \\
\text { the provisions of a particular standard, technical } \\
\text { report, or set of guidelines }\end{array}$ \\
\hline & $\begin{array}{l}\text { Information technology-W3C Web Content } \\
\text { Accessibility Guidelines (WCAG) } 2.0 \text { [43] }\end{array}$ & 2012 & $\begin{array}{l}\text { Implemented WCAG } 2.0 \text { as an ISO standard to } \\
\text { ensure its utilization by more developers, } \\
\text { policy-makers, and managers }\end{array}$ \\
\hline & $\begin{array}{l}\text { Ergonomics-Accessible design-Accessibility of } \\
\text { information presented on visual displays of small } \\
\text { consumer products [44] }\end{array}$ & 2020 & $\begin{array}{l}\text { Designed guidance on the accessibility of visually } \\
\text { presented information on small displays for older } \\
\text { people and people with disabilities }\end{array}$ \\
\hline & $\begin{array}{l}\text { Ergonomics-Accessible design-Controls of } \\
\text { consumer products [45] }\end{array}$ & 2020 & $\begin{array}{l}\text { Accessibility requirements and recommendations for } \\
\text { controlling consumer products for older people and } \\
\text { people with disabilities }\end{array}$ \\
\hline
\end{tabular}

ISO, International Organization for Standardization.

\subsection{Accessibility Acts}

The United States and Europe are regions with strong accessibility legislation regarding the use of IT devices. In the United States, accessibility is determined by various laws for different purposes, including 
the 21st CVAA, Section 508, and Section 205 of the telecommunications act. In the United States, Section 508 regulates the rights of accessibility for IT devices, which are from a federal agency (e.g., web sites, software, and computers) [15]. In other words, according to Section 508, when federal agencies develop, procure, maintain, or use electronic technology and IT, federal employees with disabilities should have comparable access to and use information and data as the federal employees without disabilities. Further, Section 255 of the communications act (hereafter, Section 255) [34] requires telecommunications equipment and services to be accessible to, and usable by, individuals with disabilities. On January 18, 2017, the access board issued an "Information and Communication Technology (ICT) Standards and Guidelines" that updated the accessibility requirements for ICT based on Sections 508 and 255 [15]. It encompassed hardware, software, electronic content, and support documentation, as well as services accessible to people with disabilities. The major changes introduced by this documentation were as follows: Rather than merely describing product types, the documentation restructured provisions to suit the multifunctional capabilities of ICT products and added Levels A and AA of WCAG 2.0. Further, more obstacles could be covered by including provisions that considered cognitive, language, and learning disabilities. In addition, the 21st CVAA of 2010 was continuously enacted to ensure people with disabilities' access to modern IT devices [16]. The 21st CVAA is particularly appropriate in this respect since it influences the import, shipping, or sale of digital apparatus in the U.S. market. Hence, IT service or hardware operators who have entered the U.S. market are currently providing accessibility functions in conformance with the provisions of 21st CVAA. The act is divided into two titles: Title 1 includes guidelines related to communication products and services connected to data, and title 2 encompasses guidelines associated with watching videos on television or the Internet. In December 2016, the "requirements for accessibility of digital apparatus functions," which detail 11 specific functions related to video that should be followed by digital apparatus manufacturers, came into effect. Related items include volume adjustment and mute functions, closed captioning options (e.g., configuration of the font size, font color, and opacity), and playback (e.g., play, stop, and pause) functions. In Europe, a new EAA will be newly passed in the EU Member States in 2020 and shall be enacted as early as 2025 [17]. The European Commission, which is responsible for making proposals for new European legislations, has proposed this act to prevent the occurrence of any obstacles to the use of products, services, and infrastructures by persons with disabilities in Europe. Further, the EU member states have established different accessibility legislations for each country, and the aforementioned EAA is the first attempt to ensure the congruity and consistency of accessibility in Europe. Consequently, manufacturers and service providers have found products and services that comply with EAA. It is easier for them to export such products to other EU member states and, thereby, people with disabilities receive highly accessible products and services at very competitive prices. The EAA's range of products and services includes consumer hardware and operating systems, self-service terminals (e.g., automated teller, ticketing, and check-in machines), consumer equipment used for electronic communication services and audiovisual media services, and e-readers.

\subsection{Accessibility Guidelines}

With the advent of the Internet in the 1990s, the term World Wide Web (or simply, web) became popular. Since the Internet enables people to carry out diverse activities, including communication, business, and leisure activities, it influences people's social culture, economic status, politics, and personal relationships [46]. People with disabilities are one of the most vulnerable groups for social exclusion, and web accessibility has been helping these people to perceive, understand, navigate, interact with, and contribute to the web. The WCAG is intended for web content, web authoring tool, and web accessibility assessment tool developers. Accordingly, WCAG 1.0 was developed in 1999, and WCAG 2.1 was established in 2018 to develop more advanced technologies and remains relevant to this day [18]. The WCAG considers a comprehensive set of disabilities, including blindness and low vision, deafness and hearing loss, learning disabilities, cognitive limitations, limited movement, speech disabilities, photosensitivity, and combinations of these conditions. WCAG 2.1 has four principles, 13 guidelines, 
78 success criteria, and several techniques to develop web content. Among them, principles are the most important aspects, and they highlight perceivability, operability, understandability, and robustness of IT devices. The guideline is a goal that helps individuals to easily access web information; it is not testable, but helps you understand success criteria. The success criteria can be tested to ensure that the website complies with web accessibility requirements. These criteria involve three levels: A (lowest), AA, and AAA (highest). Since WCAG is a very important international guideline, various tools that automatically analyze web accessibility according to the current WCAG have been developed, as well [46].

In addition, accessibility guidelines have been developed for designers and developers in each web development company. For instance, Apple developed the design guideline that must be considered in the design of an iOS app [35] and the UI kit accessibility for iOS app developers [36]. Google developed detailed guidelines for material design and instructions for Android developers [37,38]. Moreover, Samsung developed guidelines for UX designers, which are used in designing accessibility functions in Samsung products [13]. Finally, for BBC, guidelines related to mobile web contents and mobile apps have been developed [39]. Characteristically, iOS, Android, and HTML are divided, and program codes to develop each accessibility function are summarized.

\subsection{Accessibility Standard}

The International Organization for Standardization (ISO) and the International Electrotechnical Commission (IEC) facilitate the international exchange of goods and services and standardize the promotion of cooperation in the intellectual, scientific, and economic fields. Each standard document developed in this manner has the advantage of being easy to use in collaboration with other international organizations. In terms of the accessibility of IT devices, various international standard documents have been and are being developed continuously. Table 6 depicts the standards that are directly related to the accessibility of IT devices and services. In the 2000s, documents on people's accessibility to comprehensive IT devices, such as the ISO/IEC Guide 71 and ISO/IEC TR 29138, were produced. In 2020, detailed accessibility documents focusing on specific user interfaces of IT devices, such as visual displays of small consumer products or controls of consumer products, are being developed. However, since the standard has no legal effect, it provides only limited protection to people with disabilities who use IT devices.

\section{Analysis of Accessibility Acts and Guidelines from the UX Perspective}

\subsection{Analyzing Provisions Related to IT Devices/Services}

The current study analyzes the existing accessibility provisions, guidelines, and standard documents that address the difficulties faced by people with disabilities in using IT devices. Among the various provisions, guidelines, and standard documents listed in Table 6, this study set the target range for CVAA, Section 508, EAA, and WCAG. This is because the four types of documents have strong legal effects so that the inequality in the use of IT products is insufficient to affect the sale of IT products and services. Due to the same reason, that standards that solely promote communication in non-legal and unified terms are not included in the study's scope.

In this study, Section 508 is analyzed based on the "Information and Communication Technology (ICT) standards and guidelines," which was updated in January 2017. The scope was determined for Chapter 3 (functional performance criteria), Chapter 4 (hardware), and Chapter 5 (software) in the guideline document, which were considered suitable for IT devices. An analysis of CVAA considered Title 1 (communications access) and Title 2 (video programming) and included the "requirements for accessibility of digital apparatus functions," which came into effect in 2016. For the EAA, the rules for user interface and functionality design specified for each product and service "from Section 1 to Section 7" were covered. The rules detail the items that each product or service must provide for accessibility. The EAA referred to "user interface and functionality design" in Section 1 (General 
accessibility requirements related to all products covered by this directive in accordance with article 2 (1)) of Annex 1, which was updated on April 7, 2019. Similarly, WCAG 2.1 covered the success criteria of all WCAG 2.1 levels, that is, Levels A, AA, and AAA. Through this process, 179 regulations (62 in Section 508, 24 in CVAA, 78 in WCAG, and 14 in EAA) were derived.

\subsection{Classification of ITID According to Regulations}

The detailed regulations of the collected provisions and guidelines were mapped to ITID's TIC framework. Accordingly, the study derived 187 ITIDs—62 for rehabilitation, 24 for CVAA, 80 for web, and 21 for EAA. The following rules guided the mapping process:

First, relevant provisions and guidelines were analyzed based on ITID, a difficulty that occurs when using IT devices. The physical and mental vulnerabilities that characterize people with disabilities may create problems in their use of IT devices, which, in turn, causes inequalities in life in terms of, for example, information acquisition and leisure activities. Since these three types (i.e., the physical and mental vulnerabilities, difficulties in using IT devices, and inequalities in life) are mixed in the provisions and guidelines, ITID was established as the scope of this study (Figure 1). For example, the statement "The same degree of privacy of input and output shall be provided to all individuals" of the Section 508 was analyzed outside the scope since it was judged on inequality in everyday life and part of a regulation to protect privacy.

Second, if related provisions and guidelines state that a certain function should be entered, the function is judged difficult to use and the mapping is focused on the function. For example, in the "Small Entity Compliance Guide" of CVAA [47] (p. 5), "A digital apparatus manufacturer must make functions that are used for the reception, playback, or display of video programming accessible to individuals who are blind or visually impaired. Power On/Off: Function that allows the user to turn the device on or off." In this case, the purpose of providing a "voice support function" for people with blindness or visual impairments is to prevent all users from using the "power on/off" function. Therefore, it is mapped as an "activate-functional item".

Third, for a guide format, the mapping was conducted by inferring the ITID for the guidelines to protect. For example, in the Section 508 (p. 5837), “302.7. With Limited Manipulation. Where a manual mode of operation is provided, ICT shall provide at least one mode of operation that does not require fine motor control or simultaneous manual operations." Since exerting fine motor control and ensuring simultaneous manual operation is difficult, it is mapped as a "manipulate-functional item".

Finally, when one regulation is analyzed by multiple ITID difficulties, it is mapped to multiple items. For example, the statement "2.2.3. Timing is not an essential part of the event or activity presented by the content, except for non-interactive synchronized media and real-time events" in WCAG refers to disabilities such as blindness, low vision, cognitive/language disabilities, deafness, and physical disabilities. Further, this regulation is applicable to all disabilities. In the case of blindness, low vision, cognitive/language disabilities, and deafness, the regulation was mapped to understand-visual information because visual information is related to difficulties in understanding caused by the lack of time. In the case of people with physical disabilities, it was mapped as an "activate-functional item" because the time to select a specific menu was insufficient.

\section{Results}

\subsection{ITID from the Task's Perspective}

All the 187 derived ITIDs were mapped to the task. For each task category, 88 ITIDs were analyzed for sensing, 30 for cognition, 57 for action for information interaction, and 12 for action for physical device setting. Table 7 depicts the number and provision of ITIDs for each task. Finally, Figure 2 presents the numbers of tasks mapped to ITIDs for each method. 
Table 7. Numbers of provisions for each task.

\begin{tabular}{|c|c|c|c|c|}
\hline Category & Task & Number of ITID & Relative Provision & Examples \\
\hline \multirow{3}{*}{ Sensing } & Notice & 4 & W 4 & $\begin{array}{l}\text { [W] Changes in context are initiated by user request } \\
\text { alone or a mechanism is available to turn off } \\
\text { such changes }\end{array}$ \\
\hline & Search & 3 & W 3 & $\begin{array}{l}\text { [W] In content implemented using markup languages, } \\
\text { the purpose of User Interface Components, icons, } \\
\text { and regions can be programmatically determined }\end{array}$ \\
\hline & Receive & 81 & R 36, C 3, E 9, W 33 & $\begin{array}{l}\text { [E] When the product uses color to convey information, } \\
\text { indicate an action, require a response or identify } \\
\text { elements, it shall provide an alternative to color }\end{array}$ \\
\hline \multirow{3}{*}{ Cognition } & Recognize & 16 & R 2, E $1, W 13$ & $\begin{array}{l}\text { [W] Components that have the same functionality } \\
\text { within a set of Web pages are identified consistently }\end{array}$ \\
\hline & Understand & 7 & W 7 & $\begin{array}{l}\text { [W] A mechanism for identifying the expanded form or } \\
\text { meaning of abbreviations is available }\end{array}$ \\
\hline & Manage & 7 & R 2, E 1, W 4 & $\begin{array}{l}{[\mathrm{W}] \text { Information about the user's location within a set of }} \\
\text { Web pages is available }\end{array}$ \\
\hline \multirow{7}{*}{$\begin{array}{l}\text { Action for } \\
\text { information } \\
\text { interaction }\end{array}$} & Activate & 11 & R 1, C 5, W 5 & $\begin{array}{l}\text { [C] Function that allows the user to enable or disable the } \\
\text { display of closed captioning }\end{array}$ \\
\hline & Edit & 3 & $\mathrm{R} 1, \mathrm{C} 2$ & $\begin{array}{l}\text { [C] Function that allows the user to access and change } \\
\text { configuration or setup options }\end{array}$ \\
\hline & Choose & 10 & $\mathrm{C} 8, \mathrm{~W} 2$ & $\begin{array}{l}\text { [C] Function that allows the user to select channelsand } \\
\text { programs }\end{array}$ \\
\hline & Input data & 7 & R 3, E 1, W 3 & $\begin{array}{l}{[\mathrm{R}] \text { Where provided, numeric keys shall be arranged in a }} \\
12-\text { key ascending or descending keypad layout }\end{array}$ \\
\hline & Control & 14 & R 5, C 5, E 2, W 2 & $\begin{array}{l}\text { [C] Function that allows the user to adjust the volume } \\
\text { and to mute or un-mute the volume }\end{array}$ \\
\hline & Manipulate & 4 & R 1, E 1, W 2 & $\begin{array}{l}{[R] \text { Where a manual mode of operation is provided, ICT }} \\
\text { shall provide at least one mode of operation that does } \\
\text { not require fine motor control or simultaneous } \\
\text { manual operations }\end{array}$ \\
\hline & Exchange & 8 & $\mathrm{R} 4, \mathrm{E} 3, \mathrm{~W} 1$ & $\begin{array}{l}\text { [R] Where provided, biometrics shall not be the only } \\
\text { means for user identification or control }\end{array}$ \\
\hline \multirow{3}{*}{$\begin{array}{l}\text { Action for } \\
\text { physical device } \\
\text { setting }\end{array}$} & Position & 7 & R 5, E 1, W 1 & $\begin{array}{l}\text { [E] The product shall avoid modes of operation } \\
\text { requiring extensive reach and great strength }\end{array}$ \\
\hline & Connect & 3 & $\mathrm{R} 1, \mathrm{C} 1, \mathrm{E} 1$ & $\begin{array}{l}\text { [C] Function that allows the user to select their preferred } \\
\text { input source }\end{array}$ \\
\hline & Grasp & 2 & R 1, E 1 & $\begin{array}{l}\text { [E] The product shall avoid modes of operation } \\
\text { requiring extensive reach and great strength }\end{array}$ \\
\hline
\end{tabular}

ICT, information and communication technology. $\mathrm{R}$ indicates Section 508, C indicates CVAA, E indicates EAA, and $\mathrm{W}$ indicates WCAG 2.1.

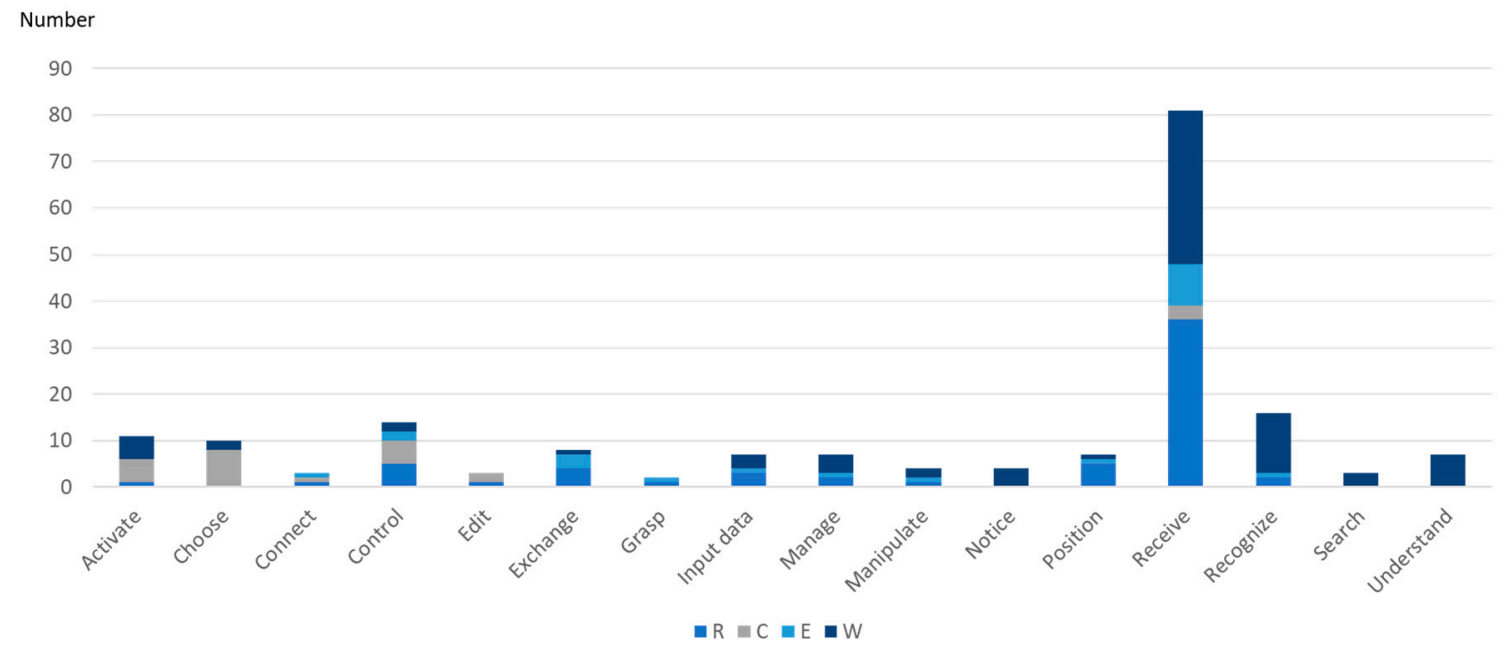

Figure 2. Depiction of the numbers of tasks by provisions and guidelines. 


\subsection{ITID from the Perspective of UIEs}

A total of 178 ITIDs were mapped to a UIE, and nine ITIDs were not mapped to the UIE. All the unmapped ITIDs were related to ITIDs in assistive technology functions or assistive products. There were 13 and 165 hardware- and software-related ITIDs, respectively. The ITIDs related to informational items were the most frequent, and the visual information was 74 , as well. Table 8 depicts an example of the numbers and provisions of ITIDs for each UIE, and Figure 3 reveals the numbers of UIEs mapped to ITIDs in each method.

Table 8. Numbers of provisions related to each UIE.

\begin{tabular}{|c|c|c|c|c|c|}
\hline Group & & UIE & $\begin{array}{l}\text { Number of } \\
\text { ITID }\end{array}$ & $\begin{array}{l}\text { Relative } \\
\text { Provision }\end{array}$ & Examples \\
\hline \multirow[b]{2}{*}{ Hardware } & \multicolumn{2}{|c|}{ User input } & 8 & R 4, E 2, W2 & $\begin{array}{l}\text { [W] Web content does not restrict use of input } \\
\text { modalities available on a platform }\end{array}$ \\
\hline & \multicolumn{2}{|c|}{ Main body } & 2 & $\mathrm{R} 1, \mathrm{~W} 1$ & $\begin{array}{l}\text { [W] Functionality that can be operated by } \\
\text { device motion or user motion can also be } \\
\text { operated by user interface components }\end{array}$ \\
\hline \multirow{4}{*}{ Software } & $\begin{array}{l}\text { Informational } \\
\text { item }\end{array}$ & Visual information & 74 & $\begin{array}{l}\text { R 25, C } 13, \text { E } 6, \\
\text { W } 30\end{array}$ & $\begin{array}{l}\text { [R] Function that allows the user to display } \\
\text { channel or program information }\end{array}$ \\
\hline & \multicolumn{2}{|c|}{ Not specific } & 26 & $\mathrm{R} 2, \mathrm{~W} 24$ & $\begin{array}{l}\text { [W] Web pages have titles that describe topic } \\
\text { or purpose }\end{array}$ \\
\hline & \multicolumn{2}{|c|}{ Functional item } & 37 & $\begin{array}{l}\text { R 10, C 10, E 3, } \\
\text { W } 14\end{array}$ & $\begin{array}{l}{[\mathrm{C}] \text { Function that allows the user to adjust the }} \\
\text { volume and to mute or un-mute the volume }\end{array}$ \\
\hline & \multicolumn{2}{|c|}{ Structural item } & 3 & $\mathrm{R} 1, \mathrm{E} 1, \mathrm{~W} 1$ & $\begin{array}{l}\text { [W] Navigational mechanisms that are } \\
\text { repeated on multiple Web pages within a set of } \\
\text { Web pages occur in the same relative order } \\
\text { each time they are repeated, unless a change is } \\
\text { initiated by the user }\end{array}$ \\
\hline
\end{tabular}

UIE, user interface element; ICT, information and communication technology. R indicates Section 508, C indicates CVAA, E indicates EAA, and W indicates WCAG 2.1.

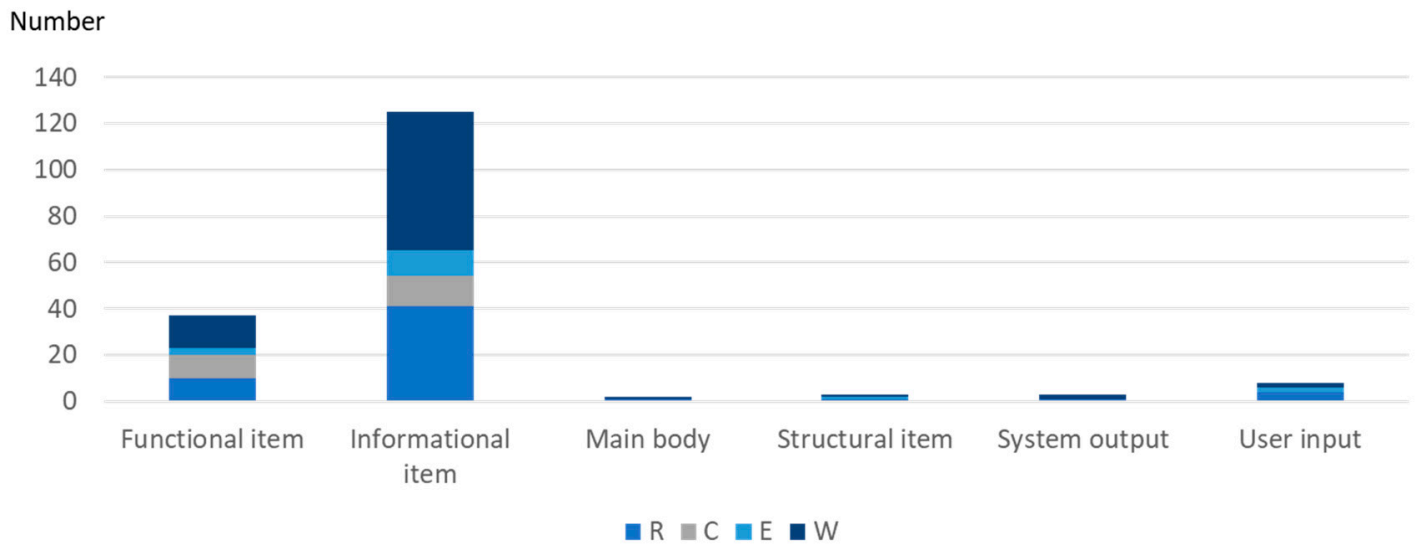

Figure 3. Depiction of the number of user interface elements by provisions and guidelines.

\subsection{ITID from the Context Perspective}

Ten ITIDs were mapped to the context factor. Further, the study analyzed two user-related, four environment-related, and five device-related ITIDs. Table 9 depicts the numbers and provisions of 
ITIDs for each context, and Figure 4 reveals the numbers of context factors mapped to ITIDs for each method.

Table 9. Numbers of provisions for each context factor.

\begin{tabular}{clccl}
\hline $\begin{array}{c}\text { Primary } \\
\text { Category }\end{array}$ & Context Factor & $\begin{array}{c}\text { Number of } \\
\text { ITID }\end{array}$ & Relative Provision & Examples \\
\hline User & User profile & 2 & $\mathrm{R} \mathrm{1,E} \mathrm{1}$ & $\begin{array}{l}\text { [R] Where provided, biometrics shall not be the only } \\
\text { means for user identification or control }\end{array}$ \\
\hline Environment & Other device & 2 & $\mathrm{R} \mathrm{1,} \mathrm{C} \mathrm{1}$ & $\begin{array}{l}\text { [R] Where data connections used for input and output } \\
\text { are provided, at least one of each type of connection shall } \\
\text { conform to industry standard non-proprietary formats } \\
\text { [E] It shall provide for flexible magnification, brightness } \\
\text { and contrast for communication, information and } \\
\text { operation, as well as ensure interoperability with } \\
\text { programs and assistive devices to navigate the interface }\end{array}$ \\
\hline products & 1 & E 1 & R 2, E 2 & $\begin{array}{l}\text { [R] Software shall interoperate with assistive technology } \\
\text { [W] Content does not restrict its view and operation to a } \\
\text { single display orientation, such as portrait or landscape, } \\
\text { unless a specific display orientation is essential }\end{array}$ \\
\hline
\end{tabular}

$\mathrm{R}$ indicates Section 508, C indicates CVAA, E indicates EAA, and W indicates WCAG 2.1.

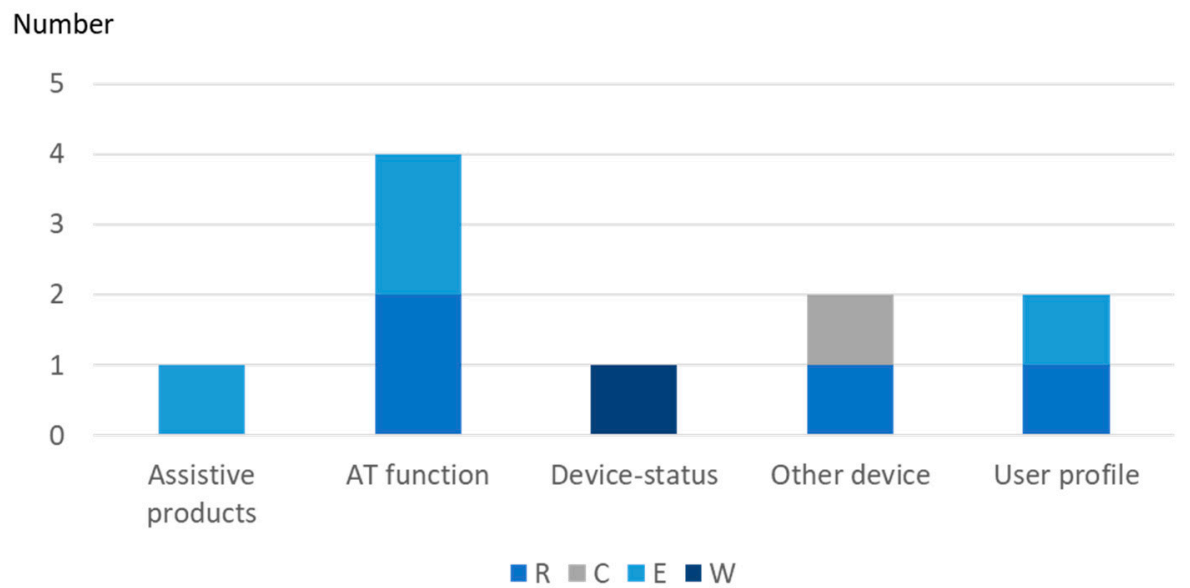

Figure 4. Numbers of context factors by provisions and guidelines.

\section{Discussion}

Based on four major accessibility provisions and guidelines, this study examined the ITIDs that existing legal provisions and guidelines protect against to ensure the equal use of IT devices by people with and without disabilities. The TIC framework was used to perform analyses by task, UIEs, and context factors. For each task category, approximately $47 \%$ of all ITIDs related to sensing, $16 \%$ related to cognition, 31\% related to the action for information interaction, and $6 \%$ related to the action for physical device settings were found. Further, for each task, the aspects receive (81), recognize (16), control (14), activate (11), and choose (10) were mapped the most (Table 7).

It is seen that the four types of provisions and guidelines that were analyzed consider the ITID on sensing to be the most important. Further, the study confirmed that the provisions and guidelines related to ITID on cognition were very small and additional provisions and guidelines must be developed to suit the continuous emergence of new IT devices. For example, for interactive speakers such as Amazon Echo and Microsoft Alexa, the main point of interaction is interpreting information with auditory information alone, without visual elements. Since the interactive speaker possesses only auditory features, it can provide useful functions for the visually impaired but cannot enable in-depth interaction. When you raise a request to search for a restaurant, you may experience difficulty in recognizing restaurant-related information when listening to the speaker's voice alone, comprehensively understanding rating information, and remembering various details pertaining to locating the desired place. Therefore, the study suggests the importance of adding regulations for ITIDs 
related to learning and remembering, which are not protected by existing provisions and guidelines. Earlier studies have often mentioned difficulties related to learning and remembering. For instance, Kim and Han [3] derived the ITID related to learning in smartphone use, as follows:

"I cannot use some programs (e.g., iTunes in iPhone) because it is too difficult to learn."

"I want to use the voiceover function, but it is too difficult for me to learn how to use it."

In addition, according to a study by Kim et al. [48], people with visual impairments sometimes memorize and use an interface layout when using a smartphone camera application. For example, the study collected the following comments:

“Even though I am a person with low vision, I remember the layout of menus and the sequence of menus first."

The current study found no provisions and guidelines related to ITID on emotion. Although ITID on emotion significantly influence users' UX while operating IT devices, it is not considered to cause inequality in everyday life. However, many of the contents of IT devices are entertainment contents, and the affective satisfaction of IT devices/services is one of the main UX factors $[49,50]$. Further, on considering the usability problems discussed by Kim et al. [48], we understand that many emotion-related issues such as "screen reader voice unfriendly" and "beeping sound pitched too high" were collected. Therefore, in future studies, it will be necessary to consider the enactment of laws related to ITID on emotion.

For each UIE category, the hardware issue was $7 \%$, whereas the software issue was $93 \%$, which mostly comprised ITID related to software. Among software, information items were 125, among which 74 ITIDs related to visual information were derived. The presence of significant volumes of visual information is inferred from the fact that most of the current provisions and guidelines address the difficulty experienced by people with visual impairments in using IT devices. Thus, when UX designers develop new UX functions/services, visual information elements should be designed considering accessibility.

Regarding context factors, only 10 ITID mappings were analyzed, which is a very small number. Since provisions and guidelines are expected to comprehensively prevent inequality, it is considered that there are only a few cases that include context. However, based on the findings of earlier studies that reveal the difficulties faced by many people with disabilities in the use of IT devices in walking and paying situations, there is a need to enact relevant provisions and guidelines in a timely manner $[3,51]$.

Therefore, the existing provisions and guidelines do not cover all the ITIDs experienced by people with disabilities when using various types of IT devices. The efficient collection of data on ITIDs experienced by users with disabilities through various methods will be helpful in the future enactment of provisions and guidelines that aim to prevent inequality. Further, accessibility designers should examine whether the relevant functions are sufficiently highlighted in products and services based on the ITIDs specified by existing provisions and guidelines. If new accessibility functions are developed for different tasks, UIEs, and context factors that have hitherto not been considered, more innovative features can be developed.

\section{Conclusions}

To our knowledge, this study is the first endeavor to analyze the existing accessibility provisions/guidelines from the perspective of UX. Based on four types of provisions and guidelines (Section 508, CVAA, EAA, WCAG), the study derived 179 regulations related to IT devices and services. We classified the ITIDs experienced by users for each regulation and analyzed 187 such ITIDs. Through this study, we could understand the types of ITIDs currently protected by provisions and guidelines and infer the direction in which protection should be established in the future. The difficulties related to ITID on sensing comprised approximately $47 \%$ of all the ITIDs, and the problems associated with 
information reception were the most protected ones. Software-related UIEs, among which visual information ranked the highest, confirmed that provisions targeting people with visual impairments were the most extensive. Further, the total number of ITIDs in the context was confirmed to be 10 . In addition, the study analyzed provisions and guidelines from the UX perspective and provided IT product designers and developers with an understanding of relevant provisions and guidelines. The accessibility provisions and guidelines comprise accessibility functions or requirements that must be satisfied by IT devices. Therefore, knowledge on relevant provisions and guidelines is helpful in developing or evaluating new accessibility functions. In the future, the same process will be conducted based on various ISO documents, following which the aspects covered by standard documents will be confirmed. In order to comprehensively study the attributes and types of the ITID concept, further research is needed for users with ITID experiences, such as the disabled and the elderly.

Author Contributions: Conceptualization and writing—original draft preparation, H.K.K.; writing-review and editing, J.P. All authors have read and agreed to the published version of the manuscript.

Funding: This work was supported by the Technology Innovation Program (20006702, Development of a personal e-mobility for vulnerable people through the application of ICT) funded by the Ministry of Trade, Industry and Energy (MOTIE, Korea).

Conflicts of Interest: The authors declare no conflicts of interest.

\section{References}

1. Abascal, J.; Nicolle, C. Moving Towards Inclusive Design Guidelines for Socially and Ethically Aware HCI. Interact. Comput. 2015, 17, 484-505. [CrossRef]

2. Cisco Annual Internet Report (2018-2023). Available online: https://www.cisco.com/c/en/us/ solutions/collateral/executive-perspectives/annual-internet-report/white-paper-c11-741490.pdf (accessed on 8 April 2020).

3. Kim, H.K.; Han, S.H. Defining and classifying IT interaction disability. Behav. Inf. Technol. 2017, 36, 422-434. [CrossRef]

4. Eshet-Alkalai, Y. Digital literacy: A conceptual framework for survival skills in the digital era. J. Educ. Multimed. Hypermedia 2004, 13, 93-106.

5. Gilster, P. Digital Literacy; Wiley Computer Pub.: New York, NY, USA, 1997.

6. Hargittai, E. The digital divide and what to do about it. In New Economy Handbook; Jones, D.C., Ed.; Academic Press: San Diego, CA, USA, 2003; pp. 821-839.

7. Van Dijk, J.A.G.M. Digital divide research, achievements and shortcomings. Poetics 2006, 34, $221-235$. [CrossRef]

8. Dobransky, K.; Hargittai, E. The disability divide in internet access and use. Inform. Commun. Soc. 2006, 9, 313-334. [CrossRef]

9. Ergonomics of Human-System Interaction. Part 171: Guidance on Software Accessibility. ISO 9241-171: 2008. Available online: https://www.iso.org/standard/39080.html (accessed on 8 April 2020).

10. Information Technology_Accessibility Considerations for People with Disabilities_Part 1: User Needs; ISO/IEC TR 29138-1: 2009. Available online: https://www.iso.org/standard/45161.html (accessed on 8 April 2020).

11. Wegge, K.P.; Zimmermann, D. Accessibility, Usability, Safety, Ergonomics: Concepts, Models, and Differences. In Proceedings of the 4th HCI International Conference on Universal Access in Human-Computer Interaction, Beijing, China, 22-27 July 2017; Springer: Berlin/Heidelberg, Germany, 2007; pp. 294-301.

12. Henry, S.L.; McGee, L. Accessibility. Available online: https://www.w3.org/standards/webdesign/accessibility (accessed on 8 April 2020).

13. Kim, H.K.; Kim, C.; Lim, E.; Kim, H. How to develop accessibility UX design guideline in Samsung. In Proceedings of the 18th International Conference on Human-Computer Interaction with Mobile Devices and Services Adjunct; Association for Computing Machinery: New York, NY, USA, 2016; pp. 551-556.

14. Americans with Disabilities Act. 1990. Available online: https://www.ada.gov/ada_intro.htm (accessed on 8 April 2020). 
15. Information and Communication Technology (ICT) Final Standards and Guidelines. Available online: https://www.access-board.gov/guidelines-and-standards/communications-and-it/about-the-ict-refresh/ overview-of-the-final-rule (accessed on 8 April 2020).

16. 21st Century Communications and Video Accessibility Act (CVAA) Consumer Guide. Available online: https://www.fcc.gov/sites/default/files/21st_century_communications_and_video_accessibility_act_ cvaa.pdf. (accessed on 8 April 2020).

17. European Commission, European Accessibility Act. Available online: http://eur-lex.europa.eu/legal-content/ EN/TXT/HTML/?uri=CELEX:52015PC0615andfrom=EN (accessed on 8 April 2020).

18. Kirkpatrick, A.; Connor, J.O.; Campbell, A.; Cooper, M. Web Content Accessibility Guidelines (WCAG) 2.1. W3C. 2018. Available online: https://www.w3.org/TR/WCAG21/ (accessed on 8 April 2020).

19. Guidelines for standards developers to address the needs of older persons and persons with disabilities; ISO/IEC GUIDE 71: 2001. Available online: https://www.iso.org/standard/33987.html (accessed on 8 April 2020).

20. Bawden, D. Information and digital literacies: A review of concepts. J. Doc. 2001, 57, 218-259. [CrossRef]

21. Lin, T.B.; Li, J.Y.; Deng, F.; Lee, L. Understanding new media literacy: An explorative theoretical framework. J. Educ. Technol. Soc. 2013, 16, 160-170.

22. Van Deursen, A.J.A.M.; Van Dijk, J.A.G.M. Modeling traditional literacy, internet skills and internet usage: An empirical study. Interact. Comput. 2016, 28, 13-26. [CrossRef]

23. WHO. International Classification of Functioning, Disability and Health: ICF; World Health Organization: Geneva, Switzerland, 2001.

24. Sutcliffe, A. Task analysis, systems analysis and design: Symbiosis or synthesis? Interact. Comput. 1989, 1, 6-12. [CrossRef]

25. Ergonomic Requirements for Office Work with Visual Display Terminals (VDTs). Part 11: Guidance on Usability; ISO 9241-11: 1998. Available online: https://www.iso.org/standard/16889.html (accessed on 8 April 2020).

26. Han, S.H.; Yun, M.H.; Kim, K.; Kwahk, J. Evaluation of product usability: Development and validation of usability dimensions and design elements based on empirical models. Int. J. Ind. Ergon. 2000, 26, 477-488. [CrossRef]

27. Kiljander, H. Evolution and Usability of Mobile Phone Interaction Styles. Ph.D. Thesis, Helsinki University of Technology, Espoo, Finland, 2004.

28. Park, W.; Han, S.H.; Kang, S.; Park, Y.S.; Chun, J. A factor combination approach to developing style guides for mobile phone user interface. Int. J. Ind. Ergon. 2011, 41, 536-545. [CrossRef]

29. Barnard, L.; Yi, J.S.; Jacko, J.A.; Sears, A. Capturing the effects of context on human performance in mobile computing systems. Pers. Ubiquitous Comput. 2007, 11, 81-96. [CrossRef]

30. Maguire, M. Context of use within usability activities. Int. J. Hum.-Comput. Stud. 2001, 55, 453-483. [CrossRef]

31. Park, J.; Han, H.S.; Kim, H.K.; Oh, S.; Moon, H.; Park, J. Developing and verifying a questionnaire for evaluating user value of a mobile device. Hum. Factors Ergon. Manuf. Serv. Ind. 2015, 25, 724-739. [CrossRef]

32. Hinckley, K.; Pierce, J.; Sinclair, M.; Horvitz, E. Sensing Techniques for Mobile Interaction. In Proceedings of the 13th Annual ACM Symposium on User Interface Software and Technology, San Diego, CA, USA; 2000; pp. 91-100.

33. Kane, S.K.; Wobbrock, J.O.; Smith, I.E. Getting Off the Treadmill: Evaluating Walking User Interfaces for Mobile Devices in Public Spaces. In Proceedings of the 10th International Conference on Human Computer Interaction with Mobile Devices and Services, Amsterdam, The Netherlands; 2008; pp. 109-118.

34. Telecommunications Act Section 255 Accessibility Guidelines. Available online: https://www.access-board. gov/guidelines-and-standards/communications-and-it/about-the-telecommunications-act-guidelines/ section-255-guidelines (accessed on 8 April 2020).

35. Introduction-Accessibility-Human Interface Guidelines-Apple Developer. Available online: https://developer. apple.com/design/human-interface-guidelines/accessibility/overview/introduction/ (accessed on 8 April 2020).

36. Accessibility Apple Developer Documentation. Available online: https://developer.apple.com/documentation/ uikit/accessibility/ (accessed on 8 April 2020).

37. Documentation Android Developers. Available online: https://developer.android.com/guide/topics/ui/ accessibility (accessed on 27 April 2020).

38. Accessibility Material Design. Available online: https://material.io/design/usability/accessibility.html (accessed on 8 April 2020). 
39. The BBC Standards and Guidelines for Mobile Accessibility. Available online: http://www.bbc.co.uk/ guidelines/futuremedia/accessibility/mobile (accessed on 8 April 2020).

40. Ergonomics of Human-System Interaction-Part 20: Accessibility Guidelines for Information/Communication Technology (ICT) Equipment and Services; ISO 9241-20: 2008. Available online: https://www.iso.org/standard/ 40727.html (accessed on 8 April 2020).

41. Information Technology-Accessibility Considerations for People with Disabilities-Part 2: Standards Inventory; ISO/IEC TR 29138-2: 2009. Available online: https://www.iso.org/standard/51342.html (accessed on 8 April 2020).

42. Information Technology_Accessibility Considerations for People with Disabilities-Part 3: Guidance on User Needs Mapping; ISO/IEC TR 29138-3: 2009. Available online: https://www.iso.org/standard/51342.html (accessed on 8 April 2020).

43. Information Technology-W3C Web Content Accessibility Guidelines (WCAG) 2.0; ISO/IEC 40500: 2012. Available online: https://www.w3.org/TR/WCAG20/ (accessed on 8 April 2020).

44. Ergonomics-Accessible Design-Accessibility of Information Presented on Visual Displays of Small Consumer Products; ISO 24552: 2020. Available online: https:/www.iso.org/obp/ui/\#iso:std:iso:tr:22411:ed-1: v1:en (accessed on 8 April 2020).

45. Ergonomics-Accessible Design-Controls of Consumer Products; ISO/TS 21054: 2020. Available online: https://www.iso.org/standard/69765.html (accessed on 8 April 2020).

46. Abascal, J.; Arrue, M.; Fajardo, I.; Garay, N.; Tomás, J. The use of guidelines to automatically verify Web accessibility. Univers. Access Inf. Soc. 2004, 3, 71-79. [CrossRef]

47. Small Entity Compliance Guide. Available online: https://docs.fcc.gov/public/attachments/DA-16-412A1.pdf (accessed on 8 April 2020).

48. Kim, H.K.; Han, S.H.; Park, J.; Park, J. The interaction experiences of visually impaired people with assistive technology: A case study of smartphones. Int. J. Ind. Ergon. 2016, 55, 22-33. [CrossRef]

49. Kim, H.K.; Han, S.H.; Park, J.; Park, J. Identifying affect elements based on a conceptual model of affect: A case study on a smartphone. Int. J. Ind. Ergon. 2016, 53, 193-204. [CrossRef]

50. Park, J.; Han, S.H.; Kim, H.K.; Cho, Y.; Park, W. Developing elements of user experience for mobile phones and services: Survey, interview, and observation approaches. Hum. Factors Ergon. Manuf. Serv. Ind. 2013, 23, 279-293. [CrossRef]

51. Oh, S. An analysis on SAMSUNG PAYs Accessibility for Visually impaired people: Improved system design. Korean Inst. Inf. Sci. Eng. 2018, 7, 1592-1594.

(C) 2020 by the authors. Licensee MDPI, Basel, Switzerland. This article is an open access article distributed under the terms and conditions of the Creative Commons Attribution (CC BY) license (http://creativecommons.org/licenses/by/4.0/). 